(5) A fifth set of verifying facts are such links of relationship between the various Aryan languages as geographically spoken in historical times, such links of relationship as appear to postulate a common speech in that very area above indicated, and where an ancient Aryan language still survives along with primitive Aryan customs. For such a common speech would have one class of differentiations on the Asiatic, and another on the European side, caused by the diverse linguistic reactions of conquered non-Aryan tribes on primitive Aryan speech, or the dialects of it already developed in those great river-partitioned plains.

(6) A further set of verifying facts are to be found in those which lead us more and more to a theory of the derivative origin of the classic civilizations, both of the Western and of the Eastern Aryans. Just as, between the Dnieper and the Carpathians, and between the Oxus and the Himalayas, there were such conditions as must have both compelled and invited to pass from the pastoral into a partially agricultural stage; so, in passing southward from each of these regions, the Aryans would come into contact with conditions at once compelling and inviting to pass into a yet higher stage of civilization. And in support of this all the facts may be adduced which are more and more compelling scholars to acknowledge that in preexisting Oriental civilizations the sources are to be found, not only of the Hellenic and the Italic, but of the Iranian and the Indian civilizations.

(7) Finally, if the Hellenic civilization and mythology is thus to be mainly derived from a pre-existing Oriental or "Pelasgian" civilization, it is either from such pre-existing civilizations, or from Aryans such as the Kelto-Italiots, migrating northward and southward from Pelasgian Thrace, that the civilization of Western and Northern Europe would, on this hypothesis, be traced : and a vast number of facts appear to make it more probable that the earlier civilization of Northern Europe was derived from the south than that the earlier civilization of Southern Europe was derived from the north.

The three conditions of a true solution of the problem either of Semitic or of Aryan origins appear to be these. First, the locality must be one in which such a new race could have ethnologically, and secondly philologically, arisen as a variety of the Archaian stock of white races; and thirdly, it must be such as to make easily possible the historical facts of dispersion and early civilization. And I venture to submit the above sets of facts as not inadequately, perhaps, supporting the South Russian "speculation as to the origin and home of the Aryan family."

J. S. Stuart Glennie.

The Shealing, Wimbledon Common, September 22.

\section{Mr. Dixon's Mode of Observing the Phenomena of Earthquakes.}

Mr. HAROlD Dixon's letter in NATURE of Sept I8 (p. 49I) is exceedingly interesting to seismologists. On two occasions he was able to make the only kind of observation which is of any value unless seismographs are actually employed; he has been able to make these in England, where earthquakes are rare, and I know of no record of such definite information being given by any of the trained observers in Japan, where earthquakes are so numerous. It requires great coolness to make such observations at such a time.

Seismngraphic records show that even in destructive Japanese earthquakes the vertical displacement of the ground is usually Jess than one millimetre, so that the mere difference in vertical displacement observed by $\mathrm{Mr}$. Dixon between two points in the same room must have approached five hundred times the greatest absolute vertical displacement in Japan. Mr. Dixon truly says that, if the displacement observed by him had been due to the movement of the hill itself, it must have meant a good deal, for it would have meant some hundreds of thousands of times the greatest vertical earth movement recorded by any seismograph.

When I say that Mr. Dixon's letter is interesting, I make the assumption that what he observed was not merely what anybody observes who raises his head when looking at a distant hill through a window.

3I Brunswick Square, W.C., September 24.

\section{Butterflies Bathing.}

In Nature of August 2I (p. 402) is a note taken from the Victurian Naturalist describing an observation made by
Mr. G. Lyell, Jun., of Melbourne. He states that several butterflies (Papilio macleayanus) were seen to enter the water backwards, remain partly submerged for about half a minute, and then fly off to the hill-sides refreshed with their bath. The heat of the weather is given as the cause of their action.

I should like to suggest that the insects were probably engaged in depositing their eggs. Perhaps some one who has the opportunity will ascertain if the larva of this butterfly is aquatic, or feeds on plants growing at the water's edge.

St. Olave's Grammar School, Southwark. G. A. Freeman.

\section{Surface-tension and Surface-viscosity.}

IF an oiled needle be placed on the surface of pure water, it will be supported, but if it be washed in a solution of potash, it will sink. In the first case the effect cannot be due to the surface-tension, which is much diminished by the oil. Has the viscosity of the oil anything to do with it? Also in the case of a soap-bubble, is the effect due to viscosity, and not to surfacetension; and what is the difference between surface-tension and surface-viscosity? They are both, no doubt, due to cohesion, but it is difficult to form definite conceptions of the two properties. Would any of your readers kindly answer the abıve questions, and give references to any works bearing thereon? Maxwell's "Theory of Heat," on capillarity and viscosity, does not seem to throw any light on the matter.

W. P. O.

Leicester, September 25.

\section{ON STELLAR VARIABILITY. ${ }^{1}$}

\section{II.}

HAVE before stated that the variability phenomena observed in stars of the Groups I. and II. and VI. are produced by the same cause; all differences in the details of the effects being due to the different physical nature of the central body. In Groups I. and II. it is a swarm of meteorites with which we have to deal; in Group VI. it is a condensed star of low radiation surrounded by a dense atmosphere containing carbon in some combination.

In both cases the bodies are normally dim ; in Groups I. and II. they are so because the meteorites when undisturbed are relatively free from collisions ; in Group VI. they are so for the reason stated above, the star being on the verge of extinction.

I insist upon this dimness, because the dimmer the central body the more important becomes the luminosity caused by, or set up in, secondary swarms. Further, such variability as we are now considering is unknown in the case of the hotter stars.

It is clear that phenomena produced in either group by the action of two swarms should strongly resemble each other, and that if it be found that this explanation holds good in one case it should be found to hold equally good in the other. It is to be expected then that phenomena observed in each may throw light upon the other, and that the view advanced may be tested by the differences observed.

Let us consider two hypothetical cases, to start with, in Groups I. and VI.

In Group I. we have a condensing nebula the light of which when undisturbed is say $6 \mathrm{mag}$. Round this there revolves a cometary swarm say in six time units. At periastron collisions occur which raise the light of the combined swarms to $3 \mathrm{mag}$. There is also another similar swarm revolving in say twelve time units. The conditions are such that this second swarm produces a smaller disturbance which only raises the light to $4 \frac{1}{2}$ mag. We will assume the periods to be exactly commensurable, and the apastra to occur together. It is obvious that alternate minima will be raised by this second revolving swarm, but the maxima will be constant.

In order to put results of this nature into diagrammatic form we must consider that we are dealing with certain

Continued from p. $4 \mathrm{rg}$. 
additions of light to the constant light of the star. These additions must be shown as such.

It is very important that I should point out that for this method of direct integration to be adopted a scale of light units must be employed, for the reason that the amount of light which is sufficient to produce a change of a magnitude in a faint star would only produce a change of a fraction of a magnitude in a brighter star.

Taking the light of a star of magnitude $m$ as a unit, and using the formula

$$
\mathrm{L}_{m-n}=(2.512)^{n} \mathrm{~L}_{m},
$$

in which $\mathrm{L}_{m}$ represents the light of a star of magnitude $m$ and $\mathrm{L}_{m-n}$ the light of a star $n$ magnitudes brighter, we get-

$$
\begin{aligned}
& \mathrm{L}_{m-1}=2.51 \mathrm{~L}_{m} \\
& \mathrm{~L}_{m-2}=6.31 . \mathrm{I}_{m} \\
& \mathrm{~L}_{m-3}=15.85 \mathrm{~L}_{m} \\
& \mathrm{~L}_{m-4}=39.78 \mathrm{~L}_{m} \\
& \mathrm{~J}_{m-5}=100.02 \mathrm{I}_{m}
\end{aligned}
$$

The amount of light to be added for the different magnitudes will therefore be as follows :-

Additions for one magnitude $=(2.5 \mathbf{I}-\mathbf{I}) \mathrm{L}_{m}=\mathbf{1} \cdot 5 \mathbf{I} \mathrm{L}_{m}$

$$
\begin{aligned}
& " \text { " next } "=(6.3 \mathrm{I}-2.5 \mathrm{I}) \mathrm{L}_{m}=3.80 \mathrm{~L}_{n} \\
& \text { " " , }, \quad=(15.85-6.3 \mathrm{I}) \mathrm{L}_{m}=9.54 \mathrm{~L}_{m} \\
& \text { ", " " , }=(39.78-15.85) \mathrm{L}_{m}=23.93 \mathrm{~L}_{m} \\
& \text { " ", , }, \quad=(100.02-39.78) \mathrm{L}_{m}=60^{\circ} 24 \mathrm{~L}_{m}
\end{aligned}
$$

It is obvious that these differences are in exactly the same proportion to each other as the numbers representing the light of the stars of different magnitudes, and if in our diagrams we take a certain length of line to represent the added light equivalent to one magnitude, about $2 \frac{1}{2}$ times this will represent the added light for the next magnitude, and each succeeding magnitude will be represented by a line $2 \frac{1}{2}$ times as long as the preceding one. A scale of this kind must be adopted in integrating the effects of two sources of added light, for the reason already stated.

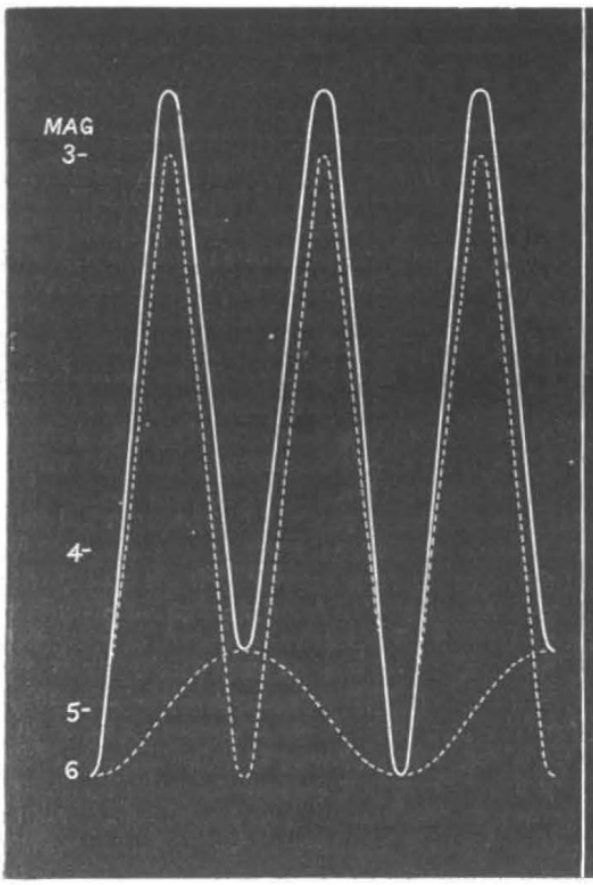

Time-units

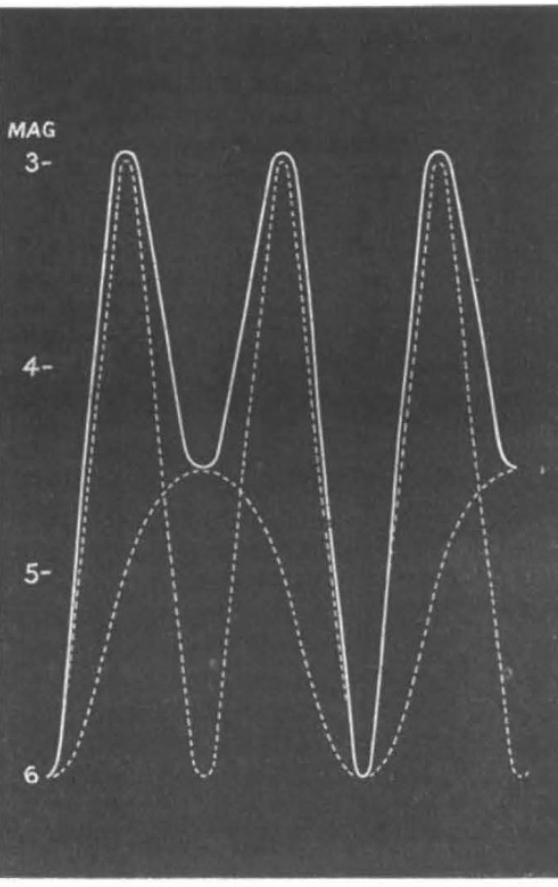

FIG. x.-Hypothetical curve in light-units.

Fig. 2.-Hypothetical curve in magnitudes.

Thus while the amount of light to be added to a sixth magnitude star, to take an instance, to increase it to the fifth is $I \frac{1}{2}$ uaits, the number of the same units to be added to a fourth magnitude star to make it a third is $9 \frac{1}{2}$. Hence the $I_{\frac{1}{2}}$ units which raise a star of the 6 th to the 5 th magnitude - that is, one whole magnitude-would only increase a fourth magnitude star by about one-sixth of a magnitude.

To graphically represent what happens when by cometary action a star is raised three magnitudes above

\begin{tabular}{|c|c|c|c|c|c|c|}
\hline \multirow[b]{2}{*}{$\begin{array}{l}\text { Magnitude } \\
\text { step. }\end{array}$} & & \multicolumn{3}{|c|}{ Light addition for } & \multirow{2}{*}{\multicolumn{2}{|c|}{$\begin{array}{c}\text { Total } \\
\text { light } \\
\text { addition. }\end{array}$}} \\
\hline & & $\begin{array}{c}\text { Integral } \\
\text { part of } \\
\text { step. }\end{array}$ & & $\begin{array}{c}\text { Fractional } \\
\text { part of } \\
\text { step. }\end{array}$ & & \\
\hline$\frac{1}{2}$ & $\cdots$ & 0 & $\cdots$ & 0.58 & $\ldots$ & 0.58 \\
\hline $\mathbf{I}$ & ... & $I \cdot 5 I$ & $\ldots$ & 0 & ... & $I \cdot 5 \mathrm{I}$ \\
\hline $1 \frac{1}{2}$ & $\ldots$ & $1 \cdot 51$ & $\ldots$ & $x \cdot 46$ & $\ldots$ & 2.97 \\
\hline 2 & $\ldots$ & $5^{\circ} 31$ & ... & o & ... & $5^{\circ} 3^{i}$ \\
\hline $2 \frac{1}{2}$ & ... & $5 \cdot 31$ & ... & $3 \cdot 66$ & $\cdots$ & $8 \cdot 97$ \\
\hline 3 & $\ldots$ & 14.85 & $\ldots$ & 0 & ... & 14.85 \\
\hline $3 \frac{1}{2}$ & $\ldots$ & 14.85 & $\ldots$ & $8 \cdot 6 r$ & ... & 23.46 \\
\hline 4 & ... & $38 \cdot 78$ & $\ldots$ & 0 & ... & $3^{8 \cdot 78}$ \\
\hline $4 \frac{1}{2}$ & $\cdots$ & $38 \cdot 78$ & $\ldots$ & 23.08 & $\ldots$ & $6 r \cdot 86$ \\
\hline 5 & ... & 100.02 & $\cdots$ & o & ... & 100.02 \\
\hline s.c. & ... & \&c. & $\cdots$ & \&c. & ... & \&c. \\
\hline
\end{tabular}
magnitude $m$, we get, in the above light-units-

$$
\begin{aligned}
& 1.512 \text { additions for one magnitude } \\
& 3.80 \text {,", the next magnitude } \\
& 9.54, \text {, , , }
\end{aligned}
$$

The sum of these numbers $=14.85$, represents the added light.

The plan on which the following curves have been

$$
\text { NO. IO92, VOL. } 42 \text { ] }
$$

drawn will be gathered from the table given below, which shows how on the above basis the light-units and magnitudes correspond :- 
In the hypothetical case represented in Fig. I the added produce constant maxima of 14.85 units, and minima constant light of the central swarm may be taken as 6 mag., and the added light of the two secondary swarms as varying from nil to $3 \mathrm{mag}$. and from nil to $4 \frac{1}{2} \mathrm{mag}$. respectively.

It is then obvious that the integrated effects of the light 3 The relative scales of light-units to brightnesses shown alternately 0 and $2^{\circ} 97$. We can in this way represent the light-curve of a star which changes its magnitude from 3 to $4 \frac{1}{2}$ and 3 to 6 alternately.

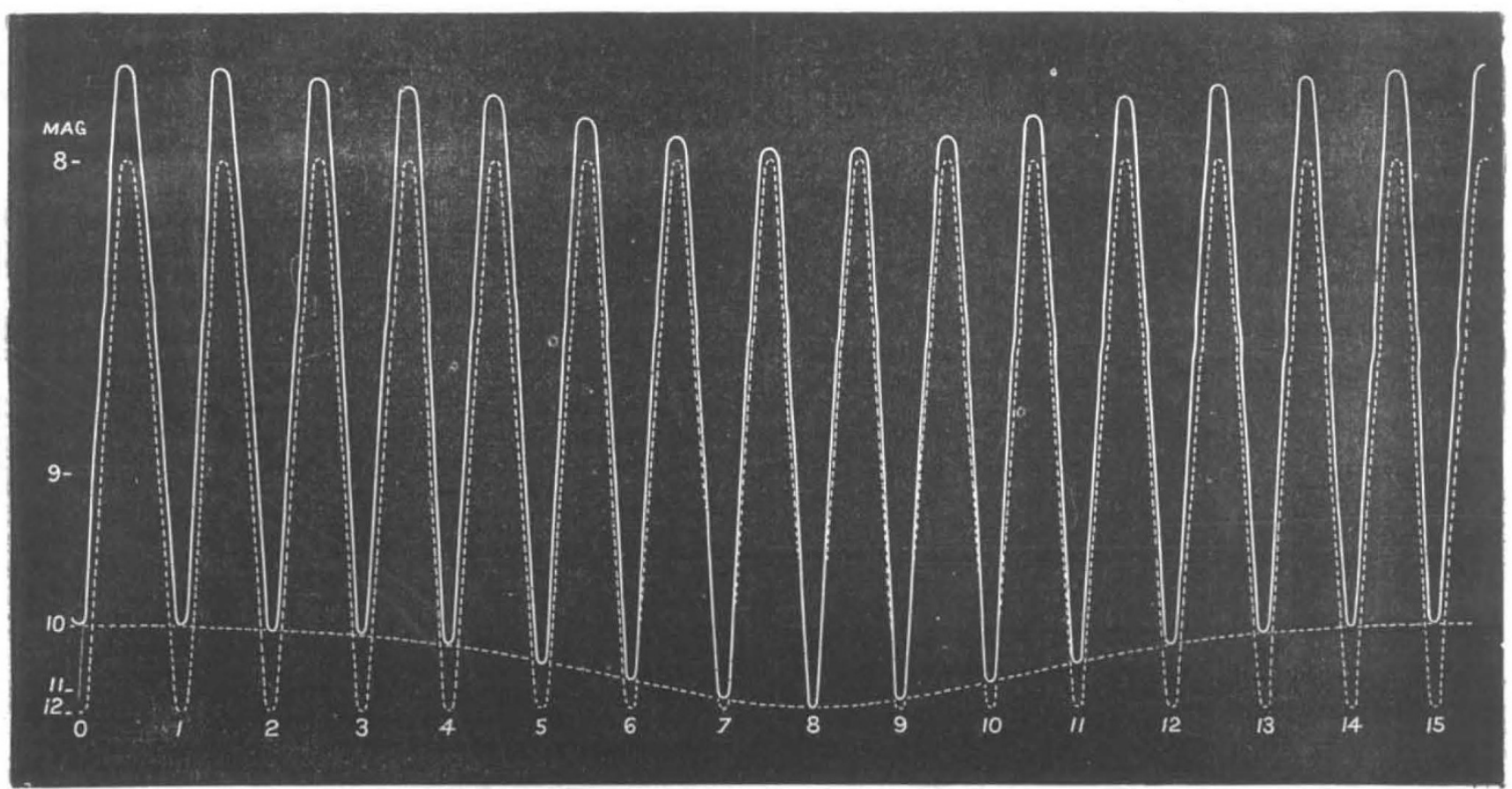

F1G. 3.-Hypothetical curve in light-units.

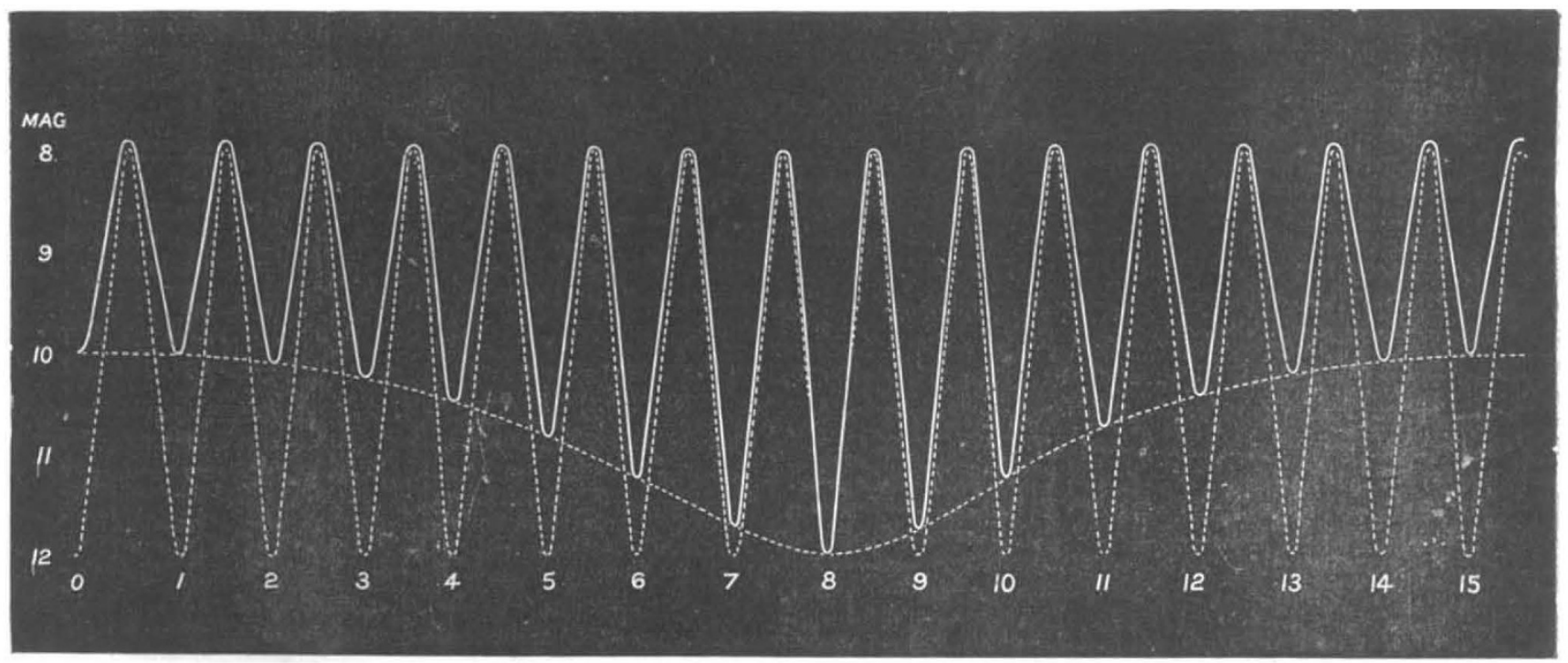

Frg. 4.-Hypothetical curve in magnitudes.

by the foregoing figures, however, enable us to transpose the diagram to one in which equal spaces represent equal differences of magnitudes. This is shown in Fig. 2.

In the diagrams, the light-curves of the two subsidiary swarms are represented by dotted lines, and the integrated result by the continunus line. One of the revolving swarms has a period of 6 units of time, and the other a period twice as long. The eccentricity of the primary swarm is such that it adds, at maximum, 14.85 light-units, while the secondary swarm adds $z^{*} 97$ light-units.

A comparison of the two diagrams will make clear what 
has already been said about the relative value of the light of one magnitude at the top and bottom of the curve.

We next take a hypothetical case from Group VI.

Here, instead of a nebula, dim owing to absence of collisions brought about by disturbances, we have to deal with a condensed body of small luminosity, the light of which is strongly absorbed by a carbon atmosphere.

We first consider the action of two subsidiary swarms, one producing more light with a short period, the other less light with a period say fifteen times longer. In fact we have one comet with an orbit of great eccentricity and short period, and another of small eccentricity and long period. We will assume the periastra to be coincident.

As the light is generally feeble, we may take the constant luminosity of the star as of the twelfth magnitude, and that it is raised to the eighth magnitude by the added light of the swarms at perihelion. We have then a difference of four magnitudes.

Proceeding as before we have :-

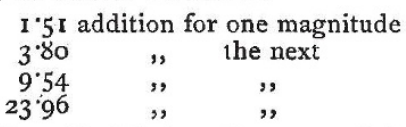

The sum of the added light gives us $38.8 \mathrm{I}$ of the lightunits adopted $=(2,512)^{4}-1$.
The continuous curve represents in Fig. 3 the integrated effects expressed in light-units of the two added light sources, and it will be seen that the result is a variable with both maxima and minima also periodically variable. But although both maxima and minima are variable by an equal number of light-units, the effect on magnitude is totally different. Whereas the minimum varies by two magnitudes, the maximum only varies by about one-tenth of a magnitude.

In the hypothetical case represented, the maximum varies between 7.8 and 7.9 , whilst the minimum varies between $100^{\circ}$ and 12 .

Like the curve for the variable of Group II., this may also be transferred to one in which equal differences of magnitudes are represented by equal spaces.

This is shown in Fig. 4, and here again it will be seen that, as in the former case, in adding a change of magnitude at the bottom of the curve to the top of the curve the magnitude-change is diminished according to the ratio of light-units.

The question now arises, Are there any stars in the heavens the phenomena of which can be represented by the hypothetical curves which we have just given? If so, we shall be justified in tracing a vera causa in the hypothesis under consideration. It may be here stated that one of the received explanations of such a variability as

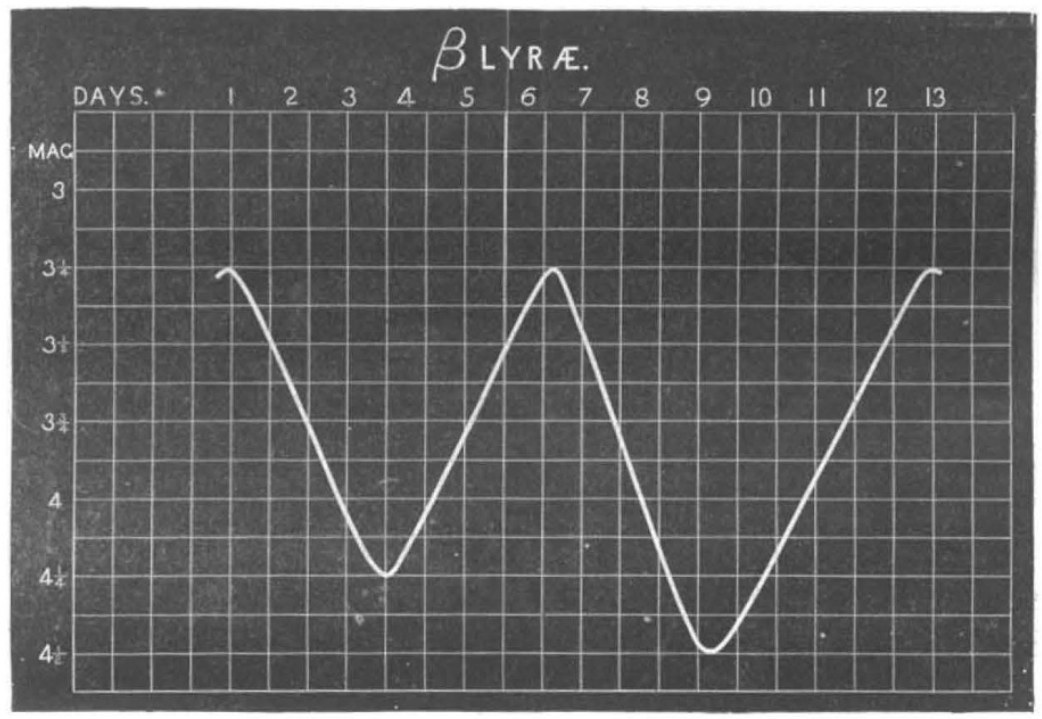

FIG. 5.-Light-curve of $\beta$ Lyræ.

is represented on our first hypothetical diagram is that due to Prof. Pickering, who conceived that the observed effect might be produced by a surface of revolution; the ratio of the axes being $5: 3$, with a dark portion at one of the ends and symmetrically situated as regards the longer axis. ${ }^{1}$

A reference to Fig. 5 will show that the hypothetical curve shown in Fig. 2 strikingly represents the actual light-curve of $\beta$ Lyræ (actual magnitudes are not in question), and I submit therefore that the well-known phenomena of that star are produced by the causes I have suggested rather than by the complicated apparatus suggested by Prof. Pickering, to say nothing of the earlier suggestions of Maupertius and others.

I append another diagram (Fig. 6) to show that the second hypothetical curve is a close approximation to the light-curve of $U$ Cygni, one of the best observed variables in Group VI. ; and here I must express my obligations to

$$
\text { "Gore in "Astronomy for Amateurs," p. } 23^{8} \text {. }
$$

NO. IO92, VOL. 42]
Mr. Knott, who has freely communicated all his observa tions of this star to me, and has permitted me to publish them in this form.

Unfortunately, though the observations are of such a high order of exactness, they are not continuous. The parts of the curve in which the line is continuous represent the actual observations. The dotted lines added are for the purpose of enabling a comparison to be made with Figs. 3 and 4 , in which the probable relations of the periods and intensities of the two hypothetic swarms are shown in light-units and magnitudes respectively.

The similarity between the hypothetic case represented and Mr. Knott's actual observations greatly strengthens my view.

It follows very clearly from the above considerations that on my hypothesis there should be frequently found rhythmical variations at the minimum, while the change at maximum is so slight that our best observers fail to notice it. 
The smaller the range, the more will both maxima and minima be affected by the subsidiary swarms. W Cygni is a case in point.

It has been before remarked that the hypothesis demands that in sparse swarms of meteorites (Groups I. and II.) the ascent to maximum, due to the sudden action of the colliding swarms, should be much more rapid than the descent to minimum, for the reason that the descent must represent a gradual cooling down of the disturbance. This more rapid ascent has been noted in

$\begin{array}{lll}\text { R Piscium ... } & \ldots \\ \text { S Vulpeculæ } & \ldots \\ \text { R Leonis Minoris } & \text { Known Group II. stars. } \\ \text { R Ursæ Majoris } & \\ \text { R Corvi } & . . & \ldots \\ \text { W Cygni } & \ldots & \ldots \\ \text { S Cassiopeiæ } & \ldots \\ \text { R Arietis } & \ldots & \ldots \\ \text { R Orionis } & \ldots & \ldots \\ \text { T Delphini } & \ldots \\ \text { T Vulpeculæ } & \ldots\end{array}$ Group not yet determined.

I have also suggested that the short minimum is a measure of the indirect disturbance, but it is easy to imagine that this short minimum will not be invariable under all conditions, and accordingly we find in $\mathrm{R}$ Persei with a period of $2 \times 2$ days, a long minimum.

In stars of Group VI., on the other hand, where we have simply to deal with the added light of comets passing perihelion, there is no reason why this should happen, indeed, it ought to be rather the other way, since comets put on their greatest brilliancy after perihelion. As a matter of fact, so far as my inquiries have gone, I have not yet come across a case of a Group VI. star showing any great difference in the times spent in rising and falling.

On the hypothesis a perfectly constant period can only occur in the case of those double swarms in which the central one has a regular figure and density. The moment this condition is departed from, seeing that the central swarm is certain to be in rotation, variation of period as well as of maximum must be expected.

Nor is this the only variation which depends upon the central body. In the absence of knowledge in each case, we must assume that the structure of the central swarm resembles that of those which have been examined in Andromeda, Ursa Major, and Canes Venatici-that is, the meteoritic density will vary locally (S Aquilæ), and

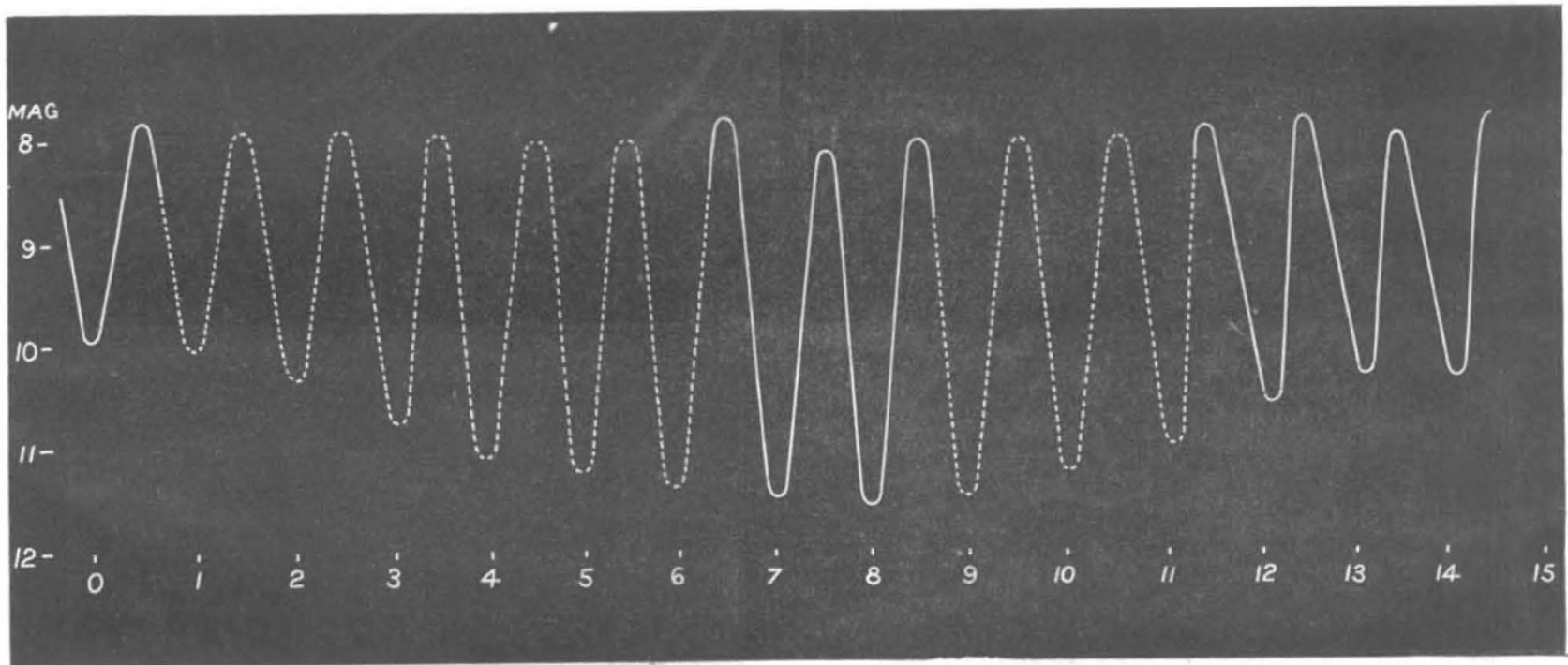

Fig. 6.-Light-curve of U Cygni, showing Mr. Knott's actual observations.

some of the observations made may be explained on the supposition that the subsidiary swarm breaks into regions in which the density is suddenly increased, as if we were noting the result of a ring being pierced ( $R$ Aurigæ).

We have only to look at Mr. Roberts's photograph of the nebula in Andromeda, and consider under what different conditions a secondary swarm might reach the same periastric distance if there were any rotation in the nebula or any movement of the nodes, to recognize the importance of taking the above points into consideration.

If there be a condition of the central body anything like that of the nebulæ named, it must be borne in mind that in the struggle for existence those swarms moving in the plane of the intakes and in the same direction, will be those that will longest survive ; hence we ought to be able to explain the light-curves on the supposition that the conditions of the secondary swarms are as stated abnve, and it is seen that we can so explain them.

When we have more than one subsidiary swarm it is easy to see that certain relations of the regular periods of their orbital motions will produce an irregularity in the compound period; so that a rhythmic change of period

$$
\text { NO. IOg2, VOL. 42] }
$$

will enable us to learn somewhat of the relation of the relative intensity and period of each of the swarms. We are really in presence of a light-tide, the elements of which can be found by analysis, as occurs with other tides nearer home.

The explanation suggested by the hypothesis of the variability of stars of Group VI. seems also to throw light upon the strange colours of some of them. R Leporis, for instance, one of the most marked variables in the group, is the famous crimson star observed by Mr. Hind. Now crimson $=$ red + blue. All these stars are red, and in many of them the absence of the blue is one of the most emphasized characteristics of the spectrum.

But suppose that the secondary swarm which adds its light at maximum is a comet with the usual carbon bands, we shall get this condition of things :-

Blue.

Bands in star Bands in subsidiary swarm ... bright $\ldots$ bright $\ldots$ bright 
LIGHT UNITS

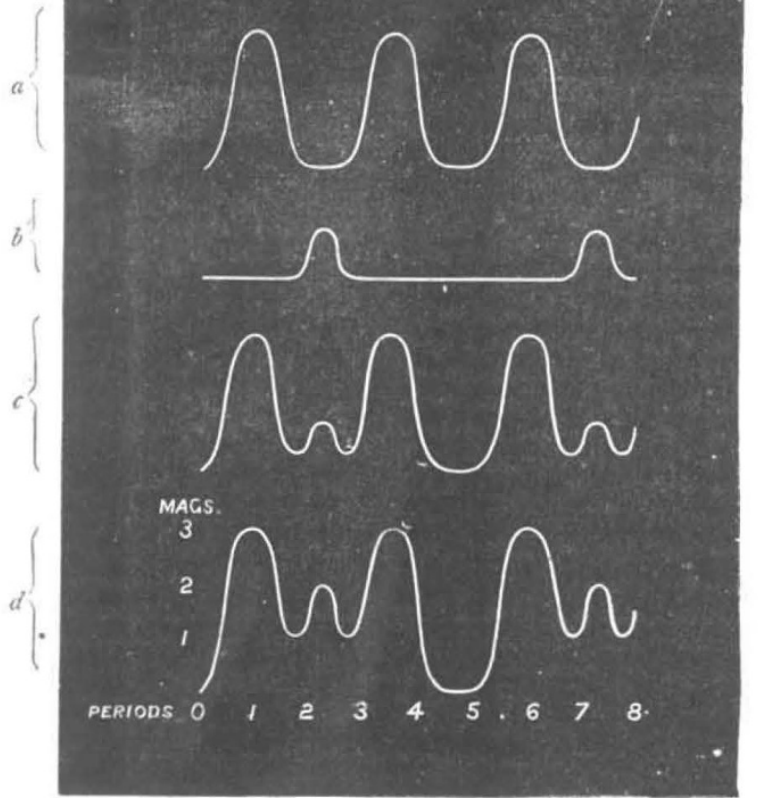

Fic. 7.-Periods 2 to I. Apastra coincident.
LIGHT UMITS
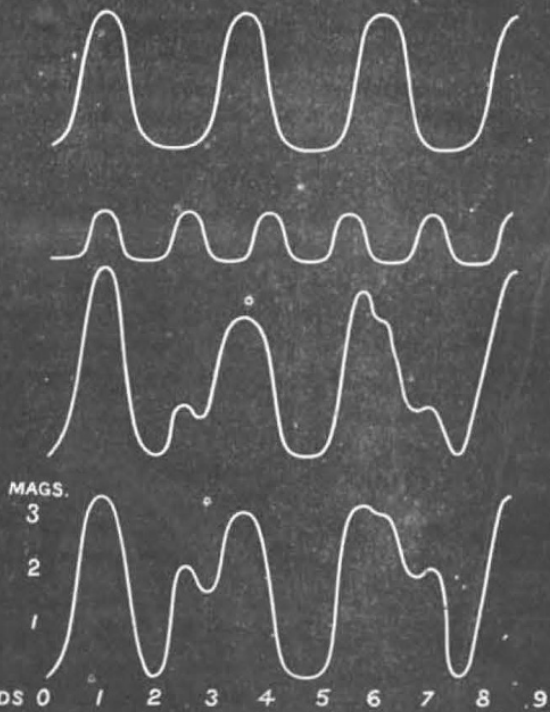

FıG. 9.-Periods 5 to 3. Periastra coincident
LIGHT UNITS
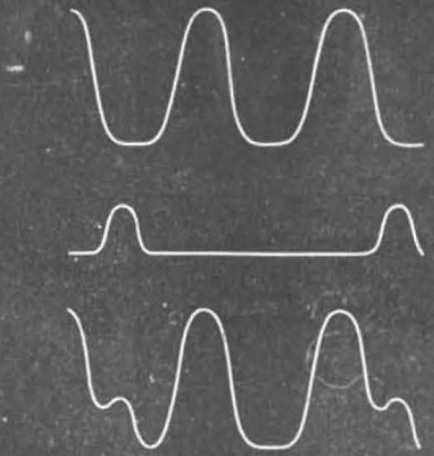

$$
\text { MAGS. }
$$

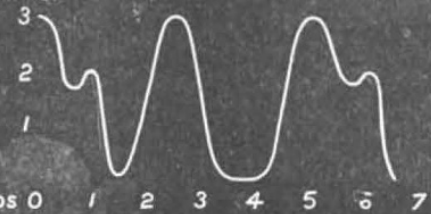

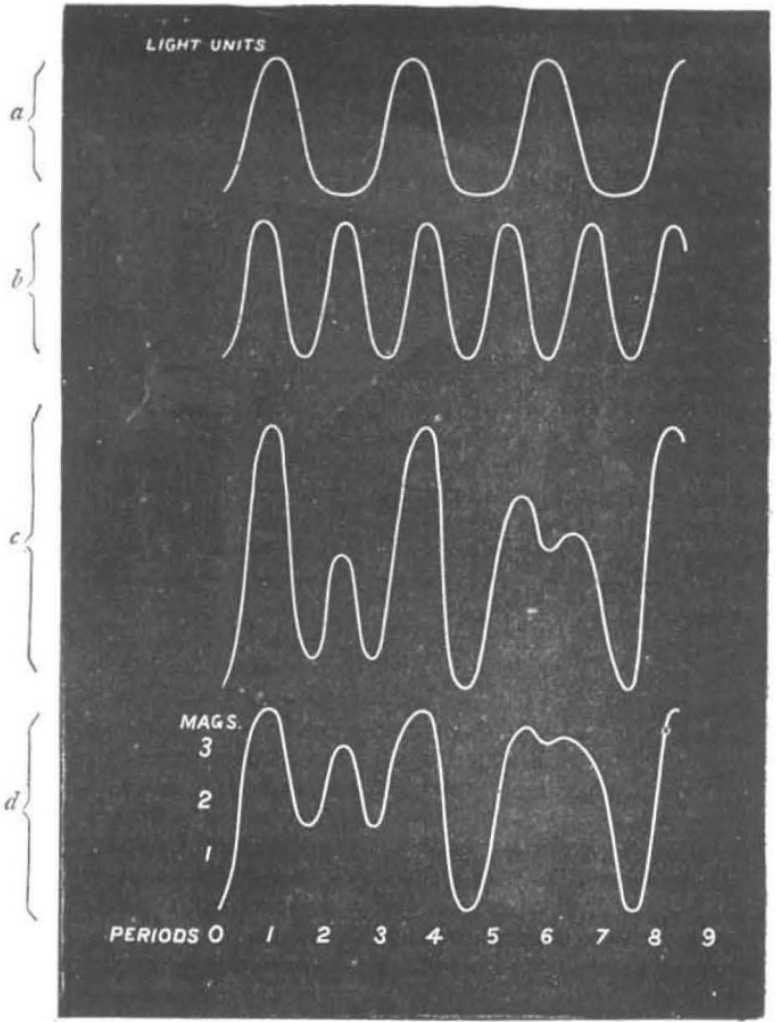

Frg. ro.-Periods 5 to 3 . Periastra not cuincideni. 
in other words, the bright fluting of carbon in the green and blue of the subsidiary swarm will just mask the absorption bands. They will pale, and the colour of the star (red) will be but slightly affected from this cause ; but the blue flutings will be clear gain to the blue end of the spectrum, and crimson will result.

If this explanation be conceded, it is clear that comets travelling round such stars are conditioned very much like comets travelling round our own sun.

The general colour of the stars in Group VI. indicates that they are near the point of invisibility, the conditions being no doubt a red or white hot crust with a strongly absorbing atmosphere. It is worth while to point out that the cessation of all radiation of light from the central body need not prevent its passing on as a variable star to Group VII. As we must assume comets to be shreds of nebulæ, i.e. meteoritic fields or streams, filched by masses which pass near them; and as the mass remains after the light has gone, there will be the same attraction at work, and we have no right to assume that it will not act in the same way as heretofore.

We can gather from this that practically there can be no permanently dark bodies in space; they must at one time or another be accompanied by comets, and they must therefore be variables.

Here a most interesting point comes in : if the phenomena of the repulsion of comets' tails, or, in other words, the repulsion of carbon in some form or other from cometary swarms, depends upon the thermal energy of the central body, this result can no longer happen when the central body has cooled down. The effect of this upon the spectrum of such a compound system is well worth inquiring into.

In the hypothetical curves I have already given, I have dealt with simple cases. But in the stars there will be certain to be complex ones brought about by the successive periastra or apastra not being coincident in the two swarms (to deal only with two), and by different relationships in the periods.

I append (Figs. 7-Io) some hypothetical curves worked out both in light-units and magnitudes, the conditions being stated for each. The paucity of actual lightcurves available prevents any inquiry as to the stars in which the conditions here imagined actually exist, but in the absence of such knowledge it is still easy to gather that different periods separating maxima, secondary minima of unequal periods, and great variations in the rise to and fall from maximum, instead of necessarily being the result of "irregularity," are all demanded by the most perfect regularity, provided we have more than one swarn to deal with under conditions anything like those employed in the hypothetical curves above given.

If there is anything of value in what I have advanced, it is quite clear that the observations of variable stars and variable star catalogues require considerable revision. First, arrangements should be made with the observatories of America and India so that the observations of a certain number of stars in the northern hemisphere should be observed as continuously as possible. The relative brightening of the bright carbon flutings in stars of Groups I. and II., and the paling of the dark carbon flutings in Group VI., should be spectroscopically watched in each case.

It is highly important also that the precise group to which each variable belongs should be determined at once, and that this datum should take the first place in the working catalogues employed.

The observations should also be recorded when made on light-curves, the time ordinate being contracted as much as possible in order that the genesis of the compound curve may be suggested as soon as possible, so that future observations can be controlled, and the greatest attention be given at the critical periods.

NO. IOg2, VOL. 42 ]
The colour-observations have done their work and have had their day: less attention need now be directed to them, and much time will be liberated thereby. ${ }^{1}$

\section{J. NORMAN LOCKYER.}

\section{THE LABYRINTHODONTS OF SWABIA. ${ }^{2}$}

SWABIA, it need scarcely be said, lies to the southeast of Stuttgart-the classic ground of the Triassic Labyrinthodonts of Germany-and since it contains the same Triassic deposits, we should naturally expect to find therein the same species of this group of Amphibians. The present memoir, remarkable alike for the splendid plates with which it is illustrated, and for the care with which the specimens have been described, is devoted to making known to the scientific world the magnificent collection of Labyrinthodont remains which have been from time to time obtained from the Swabian and Würtemberg deposits, and are now preserved in the Museums at Stuttgart, Tübingen, and Munich. Of the seventeen plates with which this work is illustrated, a large proportion are folded ones of very considerable size, while all are especially noticeable for their beauty of execution. They appear to have been printed by some special process from photographs, the finely-preserved specimens of skulls standing out with wonderful clearness from a black background. Even more noteworthy than the unrivalled execution of the plates is the perfection and beauty of the specimens themselves; and we would especially direct attention to the magnificent skull of Metopias, represented in plates xii. and xiii. of the work before us, as being the finest Labyrinthodont specimen that has ever come under our notice.

In the introduction to his memoir, the author, after summarizing what has been previously written on the subject, glances at the chief groups into which it has been proposed to divide the Labyrinthodonts. The forms treated of in the present memoir all belong to the typical group, the Euglypta of the British Association Committee of 1874, and the Stereospondyli of Prof. von Zittel. This group has been generally characterized, among other features, by the fully ossified centra of the vertebræ; but Dr. Fraas remarks that it is very difficult to be sure of the nature of their vertebræ, and that, at least in Mastodonsaurus, either the caudal vertebræ, or the vertebræ of young individuals, are of that imperfectly ossified and segmented type to which the term "rhachitomous" has been applied, so that fully ossified vertebræe only occur in the trunk region of the adult. This seems to us to indicate very clearly that the pre-Triassic Archegosauride, in which the vertebræ are always "rhachitomous," can only be separated from the Anthracosauride and Mastodonsaurida by characters of family value.

After the introductory portion, the author proceeds to discuss the geological divisions of the German Trias. Here, contrary to the views hitherto generally adopted, four main stages or groups (exclusive of the Rhætic) are recognized, viz. the Bunter-sandstein, the Muschelkalk, the Lettenkohle, and the Keuper. The separation of the Lettenkohle as a primary group distinct from the Keuper (in which it has hitherto been generally included) appears to rest on the ground that it contains many forms of Vertebrates common to the underlying Muschelkalkwhich do not occur in the typical Keuper. Thus the Sauropterygian genera Nothosaurus and Simosaurus range up into the Lettenkohle, but stop short of the true Keuper.

2 I have to thank the Astronomer-Royal and Prof. A. S. Herschel for the correction of an error into which I had fallen in the part relating to light units in the first draft of this article. The table on p. $546 \mathrm{I}$ have extracted from one of the valuable letters with which Prof. Herschel has favoured me on this subject ; it is fuller than the one it replaces.

2 "Die Labyrinthodonten der schwäbischen Trias," by Eberhard Fraas, Palcontographica, vol. xxxvi. (1889), pp. I-I58, plates i.-xvii. 